\title{
Los cuerpos del disfraz. Madre o amante. La narrativa de Elena Poniatowska
}

\author{
Rocío Oviedo Pérez de Tudela \\ Facultad de Filología \\ Universidad Complutense de Madrid
}

Existe una intrínseca relación entre imagen y memoria, especialmente en el plano de la experiencia. La memoria suele recogerse con frecuencia en imágenes, escenas del pasado que se proyectan hacia una imagen concreta. Y estas escenas, como tales imágenes, son las que construyen la novela testimonial.

Relación inicial entre la literatura y la historia. La pretensión de saltar las fronteras de los géneros y de las disciplinas en favor de uno de los elementos que más la caracterizan: su afán de autenticidad. Esto nos lleva a preguntar: ¿Es la literatura un disfraz? El texto de Elena Poniatowska es un diálogo constante con su propia biografía y con la historia, y en ambas referencias se desenvuelve su escritura a manera de palimpsesto que reúne imagen (fotografía), cartas, diarios, noticias, recortes, etc., que colaboran entre ellos de modo eficaz con objeto de convencer de su realidad en una época dominada por el pluralismo. Referencias que a su vez son indicios de un profundo deseo de actualización asumido a través del periodismo.

En el homenaje a Elena Poniatowska indiqué la relación entre imagen y biografía, fundado en el carácter testimonial de su narrativa: "Sus obras de ficción son en gran medida documentales, ya sea desde la biografía (La flor de lis o Lilus Kikus, e incluso de algún modo La piel del cielo) o desde el acontecimiento histórico (Fuerte es el silencio, La noche de Tlatelolco, Nada nadie: las voces del temblor) y artístico (Querido Diego, te abraza Quiela, Frida Kablo, La cámara seducida o Las siete cabritas). Lo documental es, no en vano, la raíz del periodismo. Un 
periodismo que nos retrotrae a los principios de la novela mexicana, fundada a su vez en el periódico. Desde El Periquillo Sarniento, la ficción ha servido, más que de diletantismo, de apoyo y divulgación de la historia y ha sido un efectivo sistema de denuncia".

En el caso singular de Elena Poniatowska tenemos dos tipos de memoria: una memoria personal construida sobre la afectividad y en gran medida autobiográfica y una memoria histórica que actúa como base fundamental de la precedente. Su concepto de lo testimonial es el eje en torno al cual gira gran parte de su poética como indica Schuessler al analizar su biografía: "para ella vivir es consignar y escribir es un lujo". Es decir, se inclina la balanza a favor de lo vivido y, expresamente, de lo socialmente vivido. La apuesta por lo testimonial justifica su valoración de la fotografía.

Respecto a la memoria autobiográfica, personal o materna, sorprende la coincidencia de los términos florales en los títulos: La flor de lis y Nomeolvides. ${ }^{1}$ Flores simbólicas de un contenido orientado a la liberación de una catarsis que abarca el paso de la infancia o la juventud a la madurez.

Respecto a la memoria histórica nos encontramos con tres modalidades que varían según el sujeto, eje del relato: una novela cuyo objeto es lo testimonial, una novela cuyo objeto es la fascinación artística (arte comprometido), y una novela cuyo objeto es lo autobiográfico. Pese a su valor histórico, en las narraciones destaca singularmente el conflicto de afectividades. Si en el tipo de novela que he titulado como puramente testimonial, nos encontramos con Hasta no verte Jesús mío o Gaby Brimmer, en la segunda son paradigmáticas Querido Diego, te abraza Quiela (centrada en el diario de Angelina Beloff), o Tinísima (biografía novelada de Tina Modotti), mientras que La flor de lis, junto con la organización de la biografía de Paula Amor, Nomeolvides, suponen un ejercicio de escritura en la que interviene la biografía personal de la autora.

Son diversas reconstrucciones históricas en las que las figuras femeninas aparecen aunadas por el criterio de libertad: en el caso de Jesusa Palancares se aplica a la soldadera y, por tanto, es una libertad múlti-

\footnotetext{
${ }^{1}$ Curiosa coincidencia también con Tina Modotti quien fotografía con frecuencia flores. La flor de lis remite al origen nobiliario de la autora, mientras que Nomeolvides, si tenemos en cuenta la dedicatoria de Paula Amor a su hija, se atiene a un doble sentido, al tiempo que refiere la sencillez de una flor que crece en la altura.
} 
ple la que se exige — social, política y afectiva — semejante, a su vez, al caso de Tina Modotti en Tinísima. En esta novela lo político se configura en relato que interfiere en lo artístico y afectivo. El conflicto amoroso es el punto de enlace con su precedente en el tiempo la figura paradigmática de la artista Angelina Beloff, en Querido Diego, te abraza Quiela. El amor en todos estos casos contradice la libertad de la que hacen gala las heroínas. Por su parte, Gaby Brimmer busca un reconocimiento social y actúa a manera de catalizador y revulsivo para la acción, del mismo modo que ocurre en La noche de Tlatelolco o en Nada, nadie, las voces del temblor.

La novela testimonial supone la construcción de una identidad y, en este caso, la construcción de la identidad femenina. Desde la aparición de la narrativa del boom el concepto de identidad incide en la literatura, un concepto que, como indica Margo Glantz (120) es todavía, si cabe, más esencial en la literatura de las escritoras. Como identidad, y por tanto como individuo, la voz de Elena Poniatowska describe el modelo histórico de la existencia: su discurso abarca las etapas formativas: la infancia, la juventud, la madurez o la vejez. Pero al mismo tiempo crea una serie de instrumentos narrativos que tratan de promover otra visión del universo femenino, como podemos apreciar tanto en Hasta no verte Jesús mío, como en su más reciente libro documental Las soldaderas (1999). Ante tal diversidad de registros he seleccionado dos que me resultan paradigmáticos en su narrativa, al ofrecer una lectura diferente, pero sin escapar a la realidad, de dos figuras casi antagónicas: la madre y la amante. Figuras que destacan de modo singular en su narrativa, y que, de algún modo, son las que se adaptan de mejor manera a la personalidad de la autora, proyectándose como una imagen literaria de sí misma.

LA IMAGEN DE LA MADRE

La imagen de la madre es figura esencial en obras como La flor de lis, pero es una imagen que de algún modo se repite casi sin variaciones en obras que remiten por igual a la ficción y a la autobiografía. (Kimberly 1997: 99-121). En casi todas estas novelas se encuentra presente el ámbito familiar, la casa, lugar paradigmático de la mujer como recordaba Bachelard en su Poética del espacio. El hogar, como indica 
Simone de Beauvoir, supone una distancia frente a los espacios habituales del hombre, y marca el inicio de la diferencia.

La dualidad, la dialéctica, es la que se desprende de las narraciones de las mujeres mexicanas: Hasta no verte Jesús mío, fue de las novelas más leídas de Elena Poniatowska, junto con La noche de Tlatelolco, al "conectar con las expectativas de un incipiente público testimonial". (Ochando: 149). Jesusa es un personaje dual, al mismo tiempo femenino y masculino. Su actividad como soldadera hace que se asimile al hombre, mientras que refleja en sus anotaciones y diálogos el proceso de una afectividad nunca satisfecha. De ahí su doble papel de protectora y protegida ("Mi papá hacía lo que yo quería. Cuando era chiquilla me consentía mucho, pero no era cariñoso. Nosotros no supimos de cariños, de apapachos, de cosas así, no. Por eso me hice grosera”). Una dialéctica que es habitual, como señala Monique Lemaitre, dentro de los parámetros de la emancipación femenina. ${ }^{2}$

En Jesusa Palancares predomina la máscara, es decir, el ocultamiento de la afectividad. Hecho coincidente con la actitud de Rosario Castellanos en el ensayo y que se lleva a cabo por necesidad: "para sobrevivir bajo los reinos masculinos la mujer lleva máscaras que disfrazan su centro auténtico y los resultados son lo que Castellanos llama la 'Antítesis de Pigmalión': 'el hombre no aspira a través de la belleza a convertir una estatua en un ser vivo, sino a un ser vivo en una estatua". (Caldwell: 654).

La muerte de la madre en Hasta no verte, Jesús mío, nos conduce a un desarraigo fundamental puesto que, prácticamente, con él se inicia la novela.

No sé si la causa era la pobreza o porque así se usaba, pero el entierro de mi madre fue muy pobre [...] Nadie se fijó que yo estaba allá dentro. De pronto él se acordó y yo le contesté desde abajo, entonces pidió que ya no echaran más tierra. Yo no me quería salir. Quería que me taparan allí con mi mamá (1969: 17).

La carencia de la madre se transfigura en la imagen del padre que la reemplaza. La niña que carece de amor y sólo encuentra atención en

\footnotetext{
2 Lemaitre (751-763); también Gnutzmann (91-104); Paley (127-132); Vilches (125-126).
} 
su padre experimenta unos celos que no se corresponden con su condición de hija.

La necesidad de ocultar el cariño se convierte en el uso continuado de la máscara. Es una afectividad frustrada que se revela casi al final de la narración. El amor es siempre una debilidad, el sentimiento se ha de vestir de frialdad para los desagradecidos. Tal es el caso de su relación con Perico, a quien le dejan para que lo críe como las hijas de su amiga Iselda no han sabido hacer. Sin embargo, las mismas palabras desmienten el rechazo, al igual que los hechos. La frialdad es el elemento necesario para que sobreviva el orgullo y conserve su dignidad:

-Mire, aquí le traigo este regalito.

- ¿A mí? ¿Por qué?

- Porque es el día de las madres.

-Llévaselo a tu tía, anda, llévaselo.

Y se regresó la Prisca con su regalo. Yo lo hubiera recibido si desde niñas agarran la costumbre de darme aunque fuera un plátano [...] Ya tenía veintidós la muchacha cuando se acuerda de venir a darme coba... Y nada menos que el día de la madre. ¡De la madre seca, porque yo fui como las mulas! (304-305).

La afectividad se vela con la máscara de la frialdad, la indiferencia, el orgullo de no necesitar nada. La escritora afirma que "el machismo permea también la literatura” (Poniatowska 2002: 2) y claramente incide en estas mujeres. Su salvaguarda en la Revolución Mexicana, como explica en la introducción a Las soldaderas, es imitar al hombre, incluso para defenderse de él, y el machismo implica la valentía y la eliminación del sentimiento. El término contrario a la debilidad es ese "no rajarse" expuesto y explicado por Octavio Paz en "Los hijos de la Malinche".

Esta formulación dual entre afectividad y represión se lleva a cabo mediante distintas técnicas o procedimientos si bien todos ellos tienden al relato testimonial. ${ }^{3}$ Una de las técnicas más empleadas por Elena Poniatowska es la entrevista y el rescate de archivos documentales,

${ }^{3}$ Señala que "la originalidad de La noche de Tlatelolco no radica tanto en la inclusión de voces múltiples sino en la peculiar organización de las mismas". Mediante recursos como "Tú" y "Elena" se hace presente el "paso del originario discurso oral dialogado al texto testimonial” (Ochando 1998: 152). 
tanto fotográficos como escritos, herencia de su trabajo periodístico. Se hace presente en lo que se podría llamar ensayo literario-histórico como La noche de Tlatelolco, ${ }^{4}$ Nada, nadie las voces del temblor, Fuerte es el silencio, Luz y luna las lunitas, Las soldaderas, etc.

Determinadas obras destacan la reconstrucción histórica mediante el uso de una técnica literaria dialogada y teatral, oral, como ocurre en Hasta no verte Jesús mío. De esta forma, sobre la base de la entrevista se edifica la novela testimonial.

La voz de otros se revela en el relato autobiográfico, en los diarios que ella misma prologa: uno de los instrumentos más efectivos para acercarnos el pasado hasta un hoy, está en Gaby Brimmery Nomeolvides.

En estas obras se establece el paradigma de la madre modelo: Sari, la madre de Gaby Brimmer y su propia madre, Paula. El deseo de sobrellevar la dificultad y superar los reveses de la vida, las equiparan a Jesusa, pero en este caso con una decidida dedicación a sus hijos y un claro concepto de la maternidad, que no aparece en Jesusa más que como carencia.

En el caso de Gaby Brimmer, afectada por una parálisis cerebral, la figura de la madre se construye mediante un collage en el que participan tanto la madre como la hija, que reclama su atención y casi exige que no se dedique a su hermano, que no lo necesita. A menudo a Sari la llama "jefe" y presenta una rebeldía frente a su autoridad, al tiempo que oculta la necesidad de su cariño:

¿Una madre que si bien comprende a su hija y le da apoyo en todo, no sabe que con su carácter apasionado y temperamental me daña porque para que no sufra más tengo que callar muchas agresiones, rebeldías, furias casi incontenibles y esconder muchas lágrimas? Mi hermano no quiere romper el cordón umbilical con mi madre y ésta lo afianza cada día más. Ahora mismo está pensando en un viaje a San Francisco para ver a su hijito (Poniatowska 1979: 17-18).

Por su parte, Elena Poniatowska la describe como "típica madre judía, sobreprotectora, ansiosa a más no poder, preocupada por el futuro, la carestía, el dinero, la vida de todos los días, el fracaso que cree

\footnotetext{
${ }^{4}$ Por su composición se asemeja al diario puesto que recoge los testimonios - como si fueran diarios - de varias personas que asistieron a los hechos, así como las informaciones de los periódicos y documentos de diverso origen.
} 
ser su vida" (24). Frente a ella, la Nani, Florencia, ofrece la fortaleza que también atribuía a Jesusa: "Florencia cree saber siempre lo que más le conviene a Gaby". Su admiración por ella trata de mantener el equilibrio con la figura de la madre, pero sin querer se privilegia.

Una situación que también aparece tanto en La flor de lis como en Nomeolvides. En ambos relatos la figura de la madre se aleja de los hijos, porque su actividad las distancia. Sin embargo, el tiempo es el que logra acercarlas nuevamente, y al mismo tiempo rodear a la figura de la madre de un hálito de misterio en el que predomina la entrega: "la veo venir con todo su desprendimiento entre las mesas [...] Cada uno de sus pasitos me conturban. Viene olvidada de sí misma, nunca ha tenido conciencia de lo que es [...] mientras llega envuelta en sus fantasmas le digo bajito que ella es lo más heroico que me ha tocado" (Amor Poniatowska: 15). Ese heroísmo es el de las mujeres, por eso la madre es la mujer por excelencia, envuelta en el silencio y en la frenética actividad de lo cotidiano que incluye "levantarse, abotonarse tantísimos botones, ir a misa, cambiar el agua de las flores, pagar el gas, ir al mercado, escribir, esperar, decir que el Pipo es un perro loco". Su iluminación la convierte en un ser extraordinario, cercano a la mística, como relata Elena Poniatowska en el epílogo.

Reflejo de esta madre universal y especial es Florencia en La piel del cielo, una madre cuyo tiempo se realiza en función de los demás: "Entre los hijos, los animales, las plantas, no había en su vida resquicio para la nostalgia [...] Todo la distraía de pensamientos que no fueran los inmediatos" (2001: 20).

Es la madre quien abre a Lorenzo al mundo de la naturaleza, la que le enseña a ver y a mirar, y encamina sus pasos hacia la astrofísica. Paradójicamente la crítica ha visto en la figura de Lorenzo una coincidencia con el marido de Elena Poniatowska, Guillermo Haro. Sin embargo, el personaje de Florencia es una simbiosis entre Paula Amor, su madre, y ella misma. Situación similar a la que refiere en su estudio de psicología Melanie Klein; 5 El mundo interno del bebé puede concebirse como la primera realidad del niño, el cual se apoya de la introyección y proyección para poner dentro o fuera de él lo que le convie-

\footnotetext{
${ }^{5}$ Melanie Klein, "Principios psicológicos del análisis infantil” (III); “Amor, culpa y reparación” (VI). En Obras completas. Julia Kristeva, analiza sus trabajos en El genio femenino 2. Melanie Klein.
} 
ne. De este modo, desde nuestra infancia existen objetos por los que manifestamos una singular preferencia y otros que odiamos; es el caso de Lorenzo con la astrofísica. Él ha aprendido a mirar el cielo a través de los ojos de su madre.

El título del presente trabajo, "Los cuerpos del disfraz" aparece reflejado en la actitud maternal que adopta la propia Elena ante la muerte de Jesusa (quien ya ha perdido su verdadero nombre, por el literario). Los papeles se invierten y si por la edad le correspondía a Jesusa la actitud protectora, es ahora Elena quien la adopta:

Jesusa dijo un día antes de morirse: 'Échenme a la calle a que me coman los perros; no gasten en mí, no quiero deberle nada a nadie'. Ahora que ha muerto, ahora que está bajo tierra y alcanzó el camposanto, quisiera mecerla con las palabras de María Sabina, tomarla en brazos como a una niña, cobijarla con todo el amor que jamás recibió, entronizarla como a tantas mujeres que hacen la historia de mi país, México, y que México no acoge sino margina. (Poniatowska 1989: 9).

LA AMANTE

Entre las biografías de Elena Poniatowska que adoptan la voz testimonial existen dos amantes paradigmáticas, Angelina Beloff (Querido Diego, te abraza Quiela, 1987) y Tina Modotti (Tinisima, 1992). Ambas refieren amores fracasados en los que se hace presente la utilización de la mujer. ${ }^{6}$ El sistema de denuncia frente a la voz del varón es la parodia, como recuerda Carmen Perilli: "La novela cumple con la función de reescribir casi paródicamente la historia de Angelina Beloff, reapropiarse de ella, contestar al discurso masculino y subvertirlo en la medida en que se otorga al personaje voz y cuerpo"; obsesionada por el amor, sin embargo será capaz de rebelarse y reconocer el olvido en el que se encuentra. ${ }^{7}$

\footnotetext{
${ }^{6}$ Hasta el punto de que Carmen Perilli titula su artículo: "La increíble y triste historia de Angelina Beloff y de su amante desalmado”. (1997).

7 Recuerda Perilli las palabras de Angelina en la novela: "hoy no quiero ser dulce, tranquila, decente, sumisa, comprensiva, resignada, las cualidades que siempre ponderan los amigos. Tampoco quiero ser maternal; Diego no es un niño grande. Diego sólo es un hombre que no escribe porque no me quiere y me ha olvidado por completo". (Poniatowska 1987: 42).
} 
Cobo Borda al analizar Tinísima recuerda a su vez la manipulación de la mujer en el entorno político, lo que nos lleva nuevamente a la denuncia explícita en Hasta no verte Jesús mío y Las soldaderas.

La otra vuelta de tuerca de la historia muestra el reverso escuálido, con que el imperialismo soviético arrojó a las playas de América sus detritus: ambiciones políticas tan obsoletas como sus maquinarias. En estos engranajes oxidados quedó atrapada Tina Modotti [...] Queda esta novela y las fotos conmovedoras de sus amantes muertos, de los pobres de este mundo, de las mujeres indígenas mexicanas... (Cobo Borda: 240).

Mujeres que viven el proceso del artista y que permanecen opacadas ante el éxito o el protagonismo del varón, ya sea Diego Rivera, Julio Antonio Mella o Tony Weston. El valor de Elena es rescatarlas del anonimato, situarlas en el objetivo de su cámara, retratarlas a ellas mientras ellas retratan el mundo.

Como señala Freud en "Introducción al narcisismo" (1915), se elige a la persona en relación con uno mismo. La confesión de estas mujeres, Tina o Angelina, su intensa vitalidad, nos hablan de un paralelo con la escritora.

Sin embargo, no siempre le cabe a la mujer el papel de víctima. De hecho en sus dos colecciones de cuentos De noche vienes (1983), o Tlapalería (2003) surge un amplio espectro de tipologías que nos muestran otros tantos procesos amorosos. De algún modo suponen un contraste, una desmitificación del sentimiento.

Tres tipologías de amantes aparecen en los cuentos, dos dominantes y una dominada, violada. Manuela y Esmeralda, como veremos, ocupan un lugar semejante al de la madre para el hombre, mientras que Luisa, en "Las pachecas", es víctima de la agresividad gratuita y de la indiferencia, incluso en el ámbito familiar.

Manuela, la maestra de "La ruptura", hipnotizada por la juventud y el salvajismo de Juan, queda paralizada: "Así son las mujeres enamoradas: como moscas panzonas que se dejan porque están llenas de azúcar" (Poniatowska 1983: 90). Pero Juan cambia, evoluciona; de tigre se convierte en gato, "un gato perezoso y familiar, un blando muñeco de peluche. Y Manuela que ambicionó ser devorada, ya no oía sino levísimos maullidos". Es la decepción, la constatación de la realidad, la que le mueve a abrir la espita del gas. Pérdida del asombro que ocasio- 
na la indiferencia y culmina en la incomunicación, "desierto y soledad", "roca y silencio".

Esmeralda, en "De noche vienes" (cuento que cierra la colección y da título a la obra), hace alarde de una afectividad múltiple. Un ser salvaje ha logrado encontrar un acomodo, aprovechando la debilidad del varón, hasta que llega a contravenir las normas sociales. Sus hombres admiten su libre comportamiento, la libertad implica la ruptura del convencionalismo, lo que ya de por sí es una rareza, pues como dice García, el asistente del magistrado, el caso de Esmeralda no se conoce en mujeres.

—Así es que de cinco...

- Los cinco me necesitaban.

- Y usted pudo prodigarse.

- Tenían una urgencia muy considerable.

— ¿Y los hijos? ¿Tiene hijos?, preguntó casi con respeto.

— ¿Cómo podría tenerlos? Ellos son mis hijos, los cuido, los atiendo en todo, no tendría tiempo (Poniatowska 1983: 209).

Y sus "maridos" lo aceptan por su propio beneficio. Sin embargo, esta prostitución irónica y a la carta tiene su reverso, atroz, en el relato de la caída de Luisa en la prostitución en uno de sus últimos cuentos "Las pachecas"(Tlapalería, 2003). La niña violada con el consentimiento de la madre y prostituida por su hermano acaba en un centro de rehabilitación donde finalmente logra un estatus distinguido y ser el ejemplo de las residentes. Frente a Esmeralda, querida por sus hombres, nadie espera nada de esta muchacha e incluso su familia la niega. El día en que su madre ha de ir a buscarla, nadie aparece. La ilusión del primer momento ("Cuando lleguen mi jefa, el Fermín, Mateo, no me van a reconocer") cede con el paso de las horas a la desesperación; no sólo cae en la indiferencia, sino que prácticamente está muerta, pues "mordería olvido".

El olvido recuerda aquel primer relato de Angelina Beloff en Querido Diego, te abraza Quiela, donde el amor gratuito de la artista termina en la soledad. Es el reconocimiento de la vaciedad del amor cuando no existe correspondencia. Es el amor gratuito que desaparece en la nada. Desencuentros, enfrentamientos constantes con la soledad, que se repiten en Tinisima, al igual que en La piel del cielo. La mujer da, como explica en Las soldaderas, mientras el hombre agrede y recibe. 
El error de la elección amorosa se origina en la infravaloración, pues, como indica Freud, la elección de una persona se basa en la relación con uno mismo. Se ama lo que uno ha sido, lo que quisiera haber sido, a la persona que fue parte de la propia persona o a la cualidad que uno quisiera tener.

Para finalizar podemos concluir:

1) En algunas narraciones funciona esencialmente la idea de representación nostálgica ligada al pasado, de personajes que, o bien no existen, o bien su existencia se encuentra abocada a la desaparición ante el cambio de parámetros tradicionales de la condición femenina o bien por cambios históricos. Es decir, se centra en un parámetro basado en la memoria y utiliza sus recursos.

2) Dentro de este parámetro, los personajes más afectados son la figura de la madre y la amante, puesto que ambas experimentan un cambio de rol.

3) Sin embargo, tan sólo se constata el cambio experimentado a través de la amante, que conforme avanza en sus narraciones manifiesta una mayor libertad. No es el caso de la madre, para quien la autora reserva una acción dentro todavía de lo tradicional.

4) Sus personajes se encuentran profundamente ligados al sentido testimonial que ofrece la autora, mediante los contenidos y técnicas - entrevista, diario, cartas - que he especificado al comienzo.

5) Establece sus paradigmas de acuerdo con la tipología de la mujer mexicana que, al igual que sus hombres, no se raja.

6) Para llevar a cabo una crítica se vale de la parodia y la reescritura de los textos, así como del juego de espejos.

7) En todos los casos el mayor castigo es no sólo la soledad, sino el olvido.

Y todo lo lleva a efecto mediante el proceso de una escritura palimpséstica en la que destaca la experiencia vivida y contemplada, no sólo en cuanto a realidad y denuncia, sino específicamente en lo que contiene de símbolo, un símbolo que dialoga consigo mismo para ofrecernos el rostro en el espejo, los cuerpos de su disfraz narrativo fundado en la parodia. 
BibLIOGRAFíA

Amor Poniatowska, Paula. Nomeolvides. Traducción y prólogo de Elena Poniatowska. México: Plaza y Janés, 1996.

Caldwell, Wendy. "Rosario Castellanos, la mujer y su imagen"; "En busca de un centro femenino nuevo: una deconstrucción de lo femenino en dos ensayos de Rosario Castellanos". En La Torre IV.14 (1999): 654.

Cobo Borda, Juan Gustavo. "Tinísima”. En Karl Kohut. Literatura mexicana hoy. Del 68 al ocaso de la Revolución. Frankfurt: Iberoamericana, 1995.

Glantz, Margo. "Las hijas de la Malinche". En Karl Kohut. Literatura mexicana hoy. Del 68 al ocaso de la Revolución. Frankfurt: Iberoamericana, 1995.

Gnutzmann, Rita. "Tres ejemplos de escritura femenina en América Latina”. En Letras de Deusto 19 (1989): 91-104.

Kimberly-Ford, Chisholm. "Searching for Singularity: Mother-Daughter Narration in Elena Poniatowska's La flor de Lis" En Dactylus 16 (Spring, 1997).

Klein, Melanie. "Principios psicológicos del análisis infantil"; "Amor, culpa y reparación”. Obras completas. II y IV. Barcelona: Paidós, 1990.

Kristeva, Julia. El genio femenino 2. Melanie Klein. Buenos Aires: Eudeba, 2002.

Lemaitre, Monique J. "Jesusa Palancares y la dialéctica de la emancipación femenina" En Revista Iberoamericana 51 (1985): 751-763.

Ochando Aymerich. La memoria en el espejo. Aproximación a la escritura testimonial. Barcelona: Anthropos, 1998.

Paley de Francescato, Martha. "Elena Poniatowska: convergencias en La flor de Lis". En Hispamérica 62 (agosto, 1992): 127-132.

Perilli, Carmen. "La increíble y triste historia de Angelina Beloff y de su amante desalmado". En Revista Chilena de Literatura 50 (abril, 1997): 133-139.

Poniatowska, Elena. Hasta no verte Jesús mio. México: Era, 1969.

- Gaby Brimmer. México: Grijalbo, 1979.

- De noche vienes. México: Grijalbo, 1983.

- Querido Diego, te abraza Quiela. México: Era, 1987.

- "La muerte de Jesusa Palancares" En La historia en la literatura iberoamericana. Memorias de XXVI Congreso del IILI. Edición, compilación y prólogo de Raquel Chang Rodríguez. New York: The City College of the City University of New York / Ediciones del Norte, 1989.

- Las soldaderas. Fototeca Nacional del Instituto Nacional de Antropología e Historia en Pachuca. México: Era / Consejo Nacional para la Cultura y las Artes, 1999. 
Poniatowska, Elena. La piel del cielo. Madrid: Alfaguara, 2001.

- Las siete cabritas. México: Era, 2000.

- Tlapalería. México: Era, 2003.

Vilches Norat, Vanessa. "Elena Poniatowska, Tinísima". En Hispamérica 66 (diciembre, 1993): 125-126. 